\title{
Postoperative Radiotherapy for Pancreatic Cancer with Microscopically-positive Resection Margin
}

\author{
SUNMIN PARK ${ }^{1}$, SONG CHEOL KIM ${ }^{2}$, SEUNG-MO HONG ${ }^{3}$, YOUNG-JOO LEE ${ }^{2}$, KWANG-MIN PARK ${ }^{2}$, \\ DAE WOOK HWANG ${ }^{2}$, JAE HOON LEE ${ }^{2}$, KI-BYUNG SONG ${ }^{2}$, BAEK-YEOL RYOO ${ }^{4}$, \\ HEUNG-MOON JANG ${ }^{4}$, KYU-PYO KIM ${ }^{4}$, CHANGHOON YU ${ }^{4}$, EUN KYUNG CHOI ${ }^{1}$, SEUNG DO AHN ${ }^{1}$, \\ SANG-WOOK LEE ${ }^{1}$, SANG MIN YOON ${ }^{1}$, JIN-HONG PARK ${ }^{1}$ and JONG HOON KIM ${ }^{1}$ \\ Departments of ${ }^{1}$ Radiation Oncology, ${ }^{2}$ Surgery, ${ }^{3}$ Pathology, and ${ }^{4}$ Medical Oncology, Asan Medical Center, \\ University of Ulsan College of Medicine, Seoul, Republic of Korea
}

\begin{abstract}
Aim: To analyze the outcomes in pancreatic cancer $(P C)$ cases with a microscopically-positive resection margin ( $R 1$ resection) treated with postoperative radiotherapy (PORT). Patients and Methods: We retrospectively analyzed the outcomes in 62 patients who received PORT for PC with R1 resection between 2001 and 2012. All patients received three-dimensional conformal radiotherapy. Concurrent chemotherapy was administered to 58 patients. Results: The median follow-up was 20.1 months. The median survival was 22.0 months and the 3-year overall survival rate was $25 \%$. The 3-year disease-free survival and local recurrence-free survival rates were $12 \%$ and $54 \%$, respectively. Local recurrence occurred in 23 patients $(44 \%)$, distant failure in 45 (87\%), and both in 16 (31\%). By multivariate analysis, the postoperative cancer antigen 19-9 (CA19-9) level and adjuvant chemotherapy were independent prognostic factors for survival. Conclusion: PORT is associated with a relatively favorable survival outcome in $P C$ with RI resection. Chemotherapy and postoperative CA19-9 level were significant prognostic factors for survival.
\end{abstract}

Pancreatic cancer is the fourth leading cause of cancerrelated death in the United States (1). At present, surgery offers the only means of cure. Unfortunately, only $20 \%$ of patients present with resectable disease (2). Even among patients who present with localized disease, the 5-year overall survival (OS) is approximately $20 \%$, and the median survival ranges from 13 to 20 months (3).

Correspondence to: Jin-hong Park, MD, PhD Department of Radiation Oncology, Asan Medical Center, University of Ulsan College of Medicine, 86, Asanbyeongwon-gil, Songpa-Gu, Seoul, 138-736, Republic of Korea. Tel: +82 230105616, Fax: +82 230106950, e-mail: jpark@amc.seoul.kr

Key Words: Pancreatic cancer, $\mathrm{R} 1$ resection, adjuvant radiotherapy.
It is anatomically difficult to obtain a clear resection margin in pancreatic cancer and resection margin involvement has been established as a key prognostic factor in this disease. There is evidence that a higher rate of $\mathrm{R} 1$ resection (a microscopically positive margin resection) relates to poorer survival (4-6). In recent years, there has been an increasing interest in the margin status of pancreatic cancer surgical resection specimens (7). This has been mainly trigged by the introduction of a novel pathology examination technique for pancreatoduodenectomy specimens, which resulted in a significantly higher R1 resection rate than when traditional gross techniques were used (7). Recent studies have indicated that the discrepancy between margin status and clinical outcome is caused by frequent under-reporting of microscopic margin involvement (8-12). This conclusion is also supported by the ACOSOG Z5031 trial (13).

Theoretically, radiotherapy (RT) could be beneficial in improving survival outcome for patients with marginpositive pancreatic cancer. Such patients benefit from the addition of RT to adjuvant chemotherapy, a finding that became apparent only through a meta-analysis of randomized adjuvant therapy trials for pancreatic cancer (14). The natural history of patients who have a microscopically-positive margin following surgery and are treated with chemotherapy and RT has not been selectively described previously. Hence, in our current study we examined treatment outcomes in patients with pancreatic cancer with R1 resection who were treated with postoperative radiotherapy (PORT).

\section{Patients and Methods}

The eligibility criteria for the present study were adenocarcinoma of the pancreas in patients who underwent a gross total tumor resection. Patients with metastatic disease (M1), presence of another malignancy, or incomplete RT were excluded. The selection of adjuvant RT and chemotherapy was based on the preference of the radiation and medical oncologists. This study was 
Table I. Patients and treatment characteristics $(n=62)$.

\begin{tabular}{|c|c|}
\hline Characteristic & $\mathrm{n}(\%)$ \\
\hline \multicolumn{2}{|l|}{ Age (years) } \\
\hline Median & 60 \\
\hline Range & $34-79$ \\
\hline \multicolumn{2}{|l|}{ Gender } \\
\hline Male & $42(67.7)$ \\
\hline Female & $20(32.3)$ \\
\hline \multicolumn{2}{|l|}{ Histology } \\
\hline Ductal adenocarcinoma & $62(100.0)$ \\
\hline \multicolumn{2}{|l|}{ Tumor location } \\
\hline Head & $37(59.7)$ \\
\hline Body & $11(17.7)$ \\
\hline Body and tail & $5(8.1)$ \\
\hline Tail & $9(14.5)$ \\
\hline \multicolumn{2}{|l|}{ Preoperative CA19-9 } \\
\hline$\leq 37 \mathrm{U} / \mathrm{ml}$ & $41(66.1)$ \\
\hline$>37 \mathrm{U} / \mathrm{ml}$ & $20(32.3)$ \\
\hline Unavailable & $1(1.6)$ \\
\hline \multicolumn{2}{|l|}{ Preoperative CA19-9 } \\
\hline$<100 \mathrm{U} / \mathrm{ml}$ & $31(50.0)$ \\
\hline$\geq 100 \mathrm{U} / \mathrm{ml}$ & $30(48.4)$ \\
\hline Unavailable & $1(1.6)$ \\
\hline \multicolumn{2}{|l|}{ Postoperative CA19-9 } \\
\hline$\leq 37 \mathrm{U} / \mathrm{ml}$ & $41(66.1)$ \\
\hline$>37 \mathrm{U} / \mathrm{ml}$ & $18(29.0)$ \\
\hline Unavailable & $3(4.8)$ \\
\hline \multicolumn{2}{|l|}{ Type of surgery } \\
\hline PPPD & $23(37.1)$ \\
\hline PD (Whipple) & $11(17.7)$ \\
\hline Distal pancreatectomy & $19(30.6)$ \\
\hline Total pancreatectomy & $3(4.8)$ \\
\hline Subtotal pancreatectomy & $6(9.7)$ \\
\hline \multicolumn{2}{|l|}{ Vascular resection } \\
\hline Yes & $29(46.8)$ \\
\hline No & $33(53.2)$ \\
\hline \multicolumn{2}{|l|}{ Concurrent chemotherapy } \\
\hline Yes & $58(93.5)$ \\
\hline No & $4(6.5)$ \\
\hline \multicolumn{2}{|l|}{ Adjuvant chemotherapy } \\
\hline Yes & $32(51.6)$ \\
\hline No & $30(48.4)$ \\
\hline
\end{tabular}

CA19-9: Carbohydrate antigen 19-9; PPPD: pylorus-preserving pancreaticoduodenectomy; PD: pancreaticoduodenectomy.

approved by the Institutional Review Board of the Asan Medical Center (2015-1392).

All patients were treated with three-dimensional conformal radiotherapy. Patients were virtually simulated in a supine position and were treated with multiple fields with homogeneous dose calculations. The clinical target volume encompassed the tumor bed, pancreatic remnant, and the regional lymphatics including the celiac axis, superior mesenteric vessels, duodenal and hepatoportal lymph nodes, and porta hepatis for pancreatic head tumors. The planning target volume (PTV) was typically treated with 40-50.4 Gy, and the tumor bed defined by the preoperative tumor volume was boosted with a cumulative dose of up to $60 \mathrm{~Gy}$. RT was delivered in
Table II. Histopathological characteristics of the study patients.

\begin{tabular}{lc}
\hline Characteristic & $\mathrm{n}(\%)$ \\
\hline Histological grade & \\
Well-differentiated & $5(8.1)$ \\
Moderately differentiated & $47(75.8)$ \\
Poorly differentiated & $8(12.9)$ \\
Unavailable & $2(3.2)$ \\
Perineural invasion & \\
Negative & $6(9.7)$ \\
Positive & $54(87.1)$ \\
Unavailable & $2(3.2)$ \\
Lymphovascular invasion & \\
Negative & $36(58.1)$ \\
Positive & $24(38.7)$ \\
Unavailable & $2(3.2)$ \\
T-Stage & $1(1.6)$ \\
T2 & $59(95.2)$ \\
T3 & $2(3.2)$ \\
T4 & \\
N-Stage & $18(29.0)$ \\
N0 & $44(71.0)$ \\
N1 & \\
TNM stage & $18(29.0)$ \\
IIA & $42(67.7)$ \\
IIB & $2(3.2)$ \\
III &
\end{tabular}

fractions of 1.8-2.5 Gy administered 5 days a week. A PTV margin of $0.7-1.0 \mathrm{~cm}$ was then included for daily patient setup variation. The median RT dose was 55.8 Gy (range $=44-60 \mathrm{~Gy}$ ). Concurrent chemoradiotherapy was performed in 58 patients $(94 \%)$. Chemotherapy was initiated on day 1 of RT. Adjuvant chemotherapy followed by chemoradiation was administered to 32 patients (52\%). Among 58 patients, $55(95 \%)$ completed the scheduled chemotherapy. Of the 58 patients, $53(91 \%)$ received 5-fluorouracilbased chemotherapy from days 1 to 28 of RT. Five patients $(9 \%)$ were prescribed uracil/tegafur $\left(300 \mathrm{mg} / \mathrm{m}^{2} / \mathrm{d}\right)$ and leucovorin $(90 \mathrm{mg} / \mathrm{d})$ in three divided doses. Chemotherapy followed by chemoradiation was performed in 32 patients (52\%). Among these, $26(42 \%)$ completed the scheduled chemotherapy. One patient received maintenance chemotherapy at an outside hospital. The cancer involved the pancreatic head in 37 patients, the pancreatic body in 11 , both the body and tail in five, and the pancreatic tail in nine, respectively. All 62 patients received surgery followed by radiotherapy with or without adjuvant chemotherapy.

All events were measured from the date of surgery to the date of occurrence or the last follow-up visit. Local recurrence was defined as any recurrence in the primary tumor bed and regional lymphatic areas. Distant metastasis was defined as any recurrence in a systemic organ, the peritoneum, or a distant lymph node. The Kaplan-Meier method was used to estimate overall (OS), diseasefree (DFS), and local recurrence-free (LRFS) survival. Survival curves were compared using the log-rank test. A Cox proportional hazards model was used to identify prognostic factors on multivariate analysis. A $p$-value of less than 0.05 was considered statistically significant. Statistical analyses were performed with SPSS Version 18.0 (SPSS, Chicago, IL, USA). 


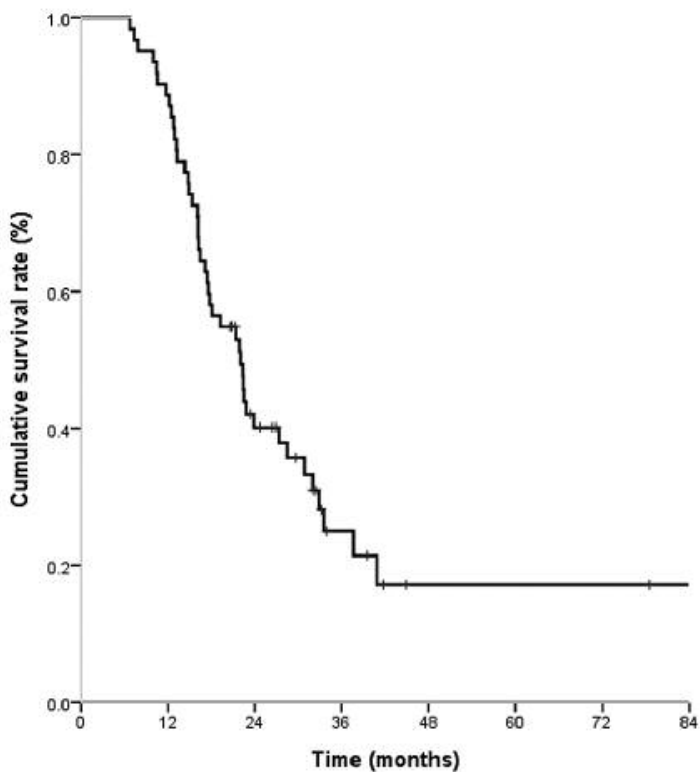

Figure 1. Overall survival curve for all 62 patients with resection margin-positive pancreatic cancer who underwent postoperative radiotherapy.

\section{Results}

We analyzed our experience with patients with pancreatic cancer treated at our center between March 2000 and December 2012. Among 424 patients who were treated by surgical resection for pancreatic cancer but had microscopically positive resection margins, a total of 73 patients were treated with PORT. Of these 73 patients, 11 were ineligible for the following reasons. Three patients were excluded due to distant metastasis at the time of surgery. One patient was excluded due to other malignancy. Another seven patients were excluded due to incomplete RT. Thus, a total of 62 patients were treated with adjuvant RT. The patient characteristics are summarized in Tables I and II. The median age was 60 years (range $=34-79$ years), and the male/female patient ratio was 2.1. The preoperative cancer antigen 19-9 (CA19-9) level was measured in 61 patients (99\%) and postoperative CA19-9 level in 59 patients (95\%). Of all patients, 37 (60\%) had pancreatic head cancer, 59 had pathological T3 tumors $(95 \%)$, one had T2 tumors (2\%), and two had T4 tumors $(3 \%)$. Positive lymph nodes were found in 44 patients $(71 \%)$.

The median follow-up duration was 20.1 months (range=3.4-84.7) for the surviving patients. The median OS and DFS were 22.0 and 11.3 months, respectively. The 3year OS rate was $25.0 \%$ and the 3-year DFS rate was $11.7 \%$ (Figures 1 and 2). The 3-year LRFS rate was $54.1 \%$ (Figure 3). The 3-year distant metastasis-free survival rate

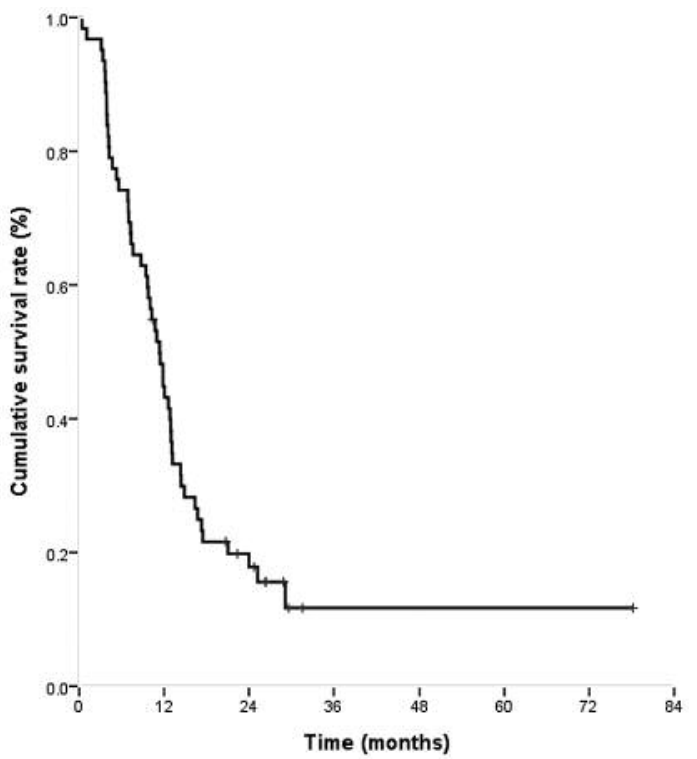

Figure 2. Disease free-survival curve for all 62 patients with resection margin-positive pancreatic cancer who underwent postoperative radiotherapy.

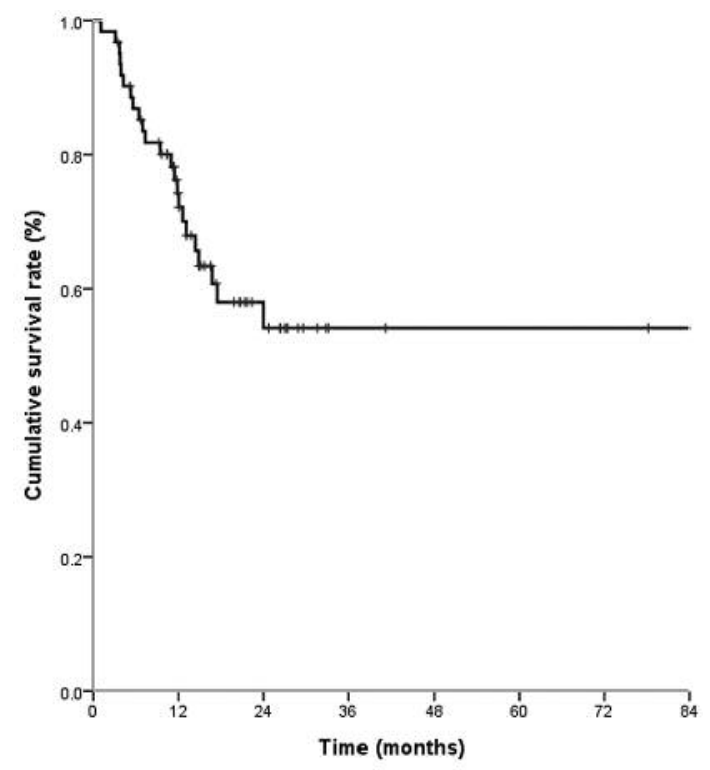

Figure 3. Local recurrence-free survival curve for all 62 patients with resection margin-positive pancreatic cancer who underwent postoperative radiotherapy.

was $18.2 \%$. Local recurrence occurred in 23 patients $(44.2 \%)$, distant failure in $45(86.5 \%)$, and both in 16 $(30.8 \%)$. The results of univariate analysis for associations between several variables and survival are provided in Table III. Factors associated with better OS included 
Table III. Univariate analysis of prognostic factors for overall (OS) and disease-free (DFS) survival.

\begin{tabular}{|c|c|c|c|c|c|c|}
\hline Variable & & $\mathrm{n}$ & 3 -Year OS (\%) & $p$-Value & 3-Year DFS (\%) & $p$-Value \\
\hline \multirow[t]{2}{*}{ Age } & $<60$ Years & 31 & 28.2 & 0.258 & 9.7 & 0.255 \\
\hline & $\geq 60$ Years & 31 & 24.6 & & 14.6 & \\
\hline \multirow[t]{2}{*}{ Gender } & Male & 42 & 30.9 & 0.557 & 7.8 & 0.740 \\
\hline & Female & 20 & 15.6 & & 15.0 & \\
\hline \multirow[t]{3}{*}{ Preoperative CA19-9 } & $<100 \mathrm{U} / \mathrm{ml}$ & 31 & 29.6 & 0.457 & 18.7 & 0.030 \\
\hline & $\geq 100 \mathrm{U} / \mathrm{ml}$ & 30 & 22.6 & & 10.2 & \\
\hline & Not assessed & 1 & & & & \\
\hline \multirow[t]{3}{*}{ Postoperative CA19-9 } & $\leq 37 \mathrm{U} / \mathrm{ml}$ & 30 & 37.6 & 0.009 & 19.0 & 0.009 \\
\hline & $>37 \mathrm{U} / \mathrm{ml}$ & 29 & 0 & & 7.4 & \\
\hline & Not assessed & 3 & & & & \\
\hline \multirow[t]{2}{*}{ Vascular invasion } & Positive & 30 & 30.8 & 0.748 & 15.4 & 0.998 \\
\hline & Negative & 32 & 18.5 & & 10.0 & \\
\hline \multirow[t]{2}{*}{ Vascular resection } & Positive & 29 & 41.5 & 0.228 & 13.6 & 0.127 \\
\hline & Negative & 33 & 11.9 & & 9.7 & \\
\hline \multirow[t]{3}{*}{ T-Stage } & 2 & 1 & 0 & & 0 & \\
\hline & 3 & 59 & 25.3 & 0.714 & 12.3 & 0.305 \\
\hline & 4 & 2 & 50 & 0.808 & 50 & 0.808 \\
\hline \multirow[t]{2}{*}{ N-Stage } & 0 & 18 & 18.5 & 0.595 & 20.8 & 0.883 \\
\hline & 1 & 44 & 28.2 & & 13.2 & \\
\hline \multirow[t]{3}{*}{ Lymphovascular invasion } & Positive & 24 & 34.0 & 0.922 & 13.8 & 0.561 \\
\hline & Negative & 36 & 17.0 & & 6.8 & \\
\hline & Not assessed & 2 & & & & \\
\hline \multirow[t]{3}{*}{ Perineural invasion } & Positive & 54 & 26.7 & 0.483 & 15.9 & 0.291 \\
\hline & Negative & 6 & 16.7 & & 0 & \\
\hline & Not assessed & 2 & & & & \\
\hline \multirow[t]{2}{*}{ CCRT } & Yes & 58 & 23.7 & 0.714 & 11.6 & 0.929 \\
\hline & No & 4 & 50.0 & & 25.0 & \\
\hline \multirow[t]{2}{*}{ Adjuvant CTx } & Yes & 34 & 39.4 & 0.005 & 14.3 & 0.007 \\
\hline & No & 28 & 9.6 & & 9.9 & \\
\hline \multirow[t]{2}{*}{ Tumor location } & Head & 37 & 32.7 & 0.945 & 16.2 & 0.952 \\
\hline & Non-head & 25 & 20.5 & & 8.2 & \\
\hline
\end{tabular}

CA19-9: Carbohydrate antigen 19-9; CCRT: concurrent chemoradiotherapy; CTx: chemotherapy.

postoperative CA19-9 normalization under $37 \mathrm{U} / \mathrm{ml}$ $(p=0.009)$ and adjuvant chemotherapy $(p=0.005)$. These two factors were also prognostic factors for DFS $(p=0.009$ and $p=0.007$, respectively). By multivariate analysis (Table IV), absence of adjuvant chemotherapy was an independent unfavorable factor for both OS $(p=0.018)$ and DFS $(p=0.064)$. Postoperative CA19-9 normalization was only a prognostic factor for DFS $(p=0.016)$ by multivariate analysis.

Analysis of the first site of recurrence in the 62 patients with $\mathrm{R} 1$ resection showed that treatment failure occurred in 52 cases $(84 \%)$ at 1-29 months after resection. The location of local recurrence was around the celiac axis or the superior mesenteric artery in 14, the pancreatojejunostomy site in four, the hepatoduodenal ligament in one, the afferent jejunal loop in one, the splenectomy site in one, and the portocaval area in one of the patients. The analysis of the association between locoregional failure and risk factors indicated that locoregional failure was more prevalent in patients with a high preoperative CA19-9 level (cut-off at $100 \mathrm{U} / \mathrm{ml}, 71 \%$ vs. $39 \%, p=0.004)$. Adjuvant chemotherapy was a marginallysignificant prognostic factor for LRFS (63\% vs. $40 \%$, $p=0.068$ ) (Figure 4).

In most cases, PORT was well tolerated, and the sideeffects were manageable. No treatment-related mortality or hospitalization occurred. No patient experienced weight loss greater than grade 2 during the RT period. Grade 3 or more acute toxicity was shown in ten patients (16\%). Eight patients (13\%), who received concurrent chemoradiotherapy, experienced grade 3 or greater hematological toxicity, but no neutropenia-related infection developed. One patient $(2 \%)$ had grade 3 nausea and vomiting, which subsided with supportive management. A late complication, duodenal ulcer, occurred in one patient (2\%) 12 months after PORT. This patient had received a radiation dose of $55.8 \mathrm{~Gy}$; the symptoms were controlled by oral medication. The treatment-related toxicities are summarized in Table V. 
Table IV. Multivariate analysis of prognostic factors for overall (OS) and disease-free (DFS) survival.

\begin{tabular}{|c|c|c|c|c|c|}
\hline \multirow[t]{2}{*}{ Variable } & & \multicolumn{2}{|c|}{ OS } & \multicolumn{2}{|c|}{ DFS } \\
\hline & & HR (95\% CI) & $p$-Value & HR $(95 \%$ CI $)$ & $p$-Value \\
\hline \multirow[t]{2}{*}{ Preoperative CA19-9 } & $<100$ & 1 & 0.506 & 1 & 0.665 \\
\hline & $\geq 100$ & $1.289(0.609-2.728)$ & & $1.182(0.554-2.523)$ & \\
\hline \multirow[t]{2}{*}{ Postoperative CA19-9 } & $\leq 37$ & 1 & 0.188 & 1 & 0.016 \\
\hline & $>37$ & $1.695(0.772-3.723)$ & & 2.667 (1.201-5.924) & \\
\hline \multirow[t]{2}{*}{ Adjuvant CTx } & Yes & $0.419(0.203-0.862)$ & 0.018 & $0.528(0.269-1.039)$ & 0.064 \\
\hline & No & 1 & & 1 & \\
\hline \multirow[t]{3}{*}{ T-Stage } & 2 & 1 & & 1 & \\
\hline & 3 & $0.605(0.072-5.050)$ & 0.642 & $0.283(0.033-2.408)$ & 0.248 \\
\hline & 4 & $0.716(0.039-13.157)$ & 0.822 & $0.751(0.059-9.565)$ & 0.825 \\
\hline \multirow[t]{2}{*}{$\mathrm{N}$-Stage } & 0 & 1 & 0.579 & 1 & 0.165 \\
\hline & 1 & $0.806(0.376-1.727)$ & & $0.599(0.291-1.235)$ & \\
\hline
\end{tabular}

HR: Hazard ratio; CI:confidence interval; CA19-9: carbohydrate antigen 19-9; CTx: chemotherapy.

\section{Discussion}

Surgery is the mainstay of curative treatment for patients with resectable pancreatic cancer. However, pancreatic cancer is anatomically difficult to remove. The surgeon cannot easily achieve wide retroperitoneal soft-tissue margins due to anatomic constraints $(8,15)$. The high incidence of locoregional and systemic failure after resection of pancreatic cancer indicates the need for effective adjuvant treatment (16). However, there is no consensus on the standard adjuvant therapy. The role of adjuvant chemoradiotherapy or chemotherapy is controversial because of the conflicting results from randomized controlled trials (Table VI).

The rate of $\mathrm{R} 1$ resection following pancreaticoduodenectomy for pancreatic adenocarcinoma reported in the literature varies from below $14 \%$ to $85 \%(17-20)$, and it is not known to what extent these differences reflect different pathological practices. Moreover, the definition of R1 resection in pancreatic cancer has been a point of some controversy. A positive resection margin was historically defined by the International Union Against Cancer as tumor at the resection margin(s) (21). However, The Royal College of Pathologists minimum dataset for histological reporting of pancreatoduodenectomy specimens recommends that cases with microscopic evidence of tumor extension beyond $1 \mathrm{~mm}$ of one or more resection margins should be classified as $\mathrm{R} 1(4,22)$. The ' $1-\mathrm{mm}$ rule' is a mere adoption of the definition of $\mathrm{R} 1$ in rectal cancer, which is based on meticulous correlation between measured minimum clearance and local tumor recurrence. Hence, an R1 definition based on a 1-mm clearance that is adequate for compact-growing rectal cancer, is likely to underestimate microscopic margin involvement in pancreatic cancer (20).
Table V. Treatment-related toxicities.

\begin{tabular}{lccc}
\hline Toxicity & \multicolumn{3}{c}{ Patients, n (\%) } \\
\cline { 2 - 4 } & Grade 2 or less & Grade 3 & Grade 4 or greater \\
\hline Acute & $62(100)$ & 0 & 0 \\
Weight loss & $54(87)$ & $8(12.9)$ & 0 \\
Hematological & 0 & $2(3.2)$ & 0 \\
Gastrointestinal & & $1(1.6)$ & 0 \\
Late & 0 & & 0 \\
Gastrointestinal & &
\end{tabular}

Recent scrutiny of the pathological examination of pancreatoduodenectomy specimens further revealed a stark lack of consensus regarding terminology and definitions that are key to the reporting of the resection margin status (20, 23). Despite these controversies, in the present analysis, the $1-\mathrm{mm}$ rule was applied, in conformity with the studies performed in Europe.

Resection margin involvement has been established as a key prognostic factor in pancreatic cancer $(8-10,12,24)$. In the randomized trials performed to date, the resection margin status was reported as a significant prognostic factor only in the ESPAC-3 trial. The 2-year overall survival rates in margin-negative and -positive patients were $51.4 \%$ and $43.4 \%$, and the median survival times were 24.7 and 19.9 months, respectively. The impact of surgical margin status after resection on survival is supported by several retrospective studies, summarized in Table VII $(7,10,15,18$, $23,25,26)$. In those studies, the median survival time was reported to be 17-55 months in R0 patients and 10-22 
Table VI. Selected studies of randomized adjuvant trials in pancreatic cancer.

\begin{tabular}{|c|c|c|c|c|c|c|}
\hline Trial & Treatment arms & $\begin{array}{l}\text { No. of } \\
\text { patients }\end{array}$ & $\begin{array}{c}\text { Locoregional failure } \\
\text { rate }(\%)\end{array}$ & $\begin{array}{l}\text { Survival rate }(\%) \\
\quad \text { (timepoint) }\end{array}$ & $\begin{array}{l}\text { Median survival } \\
\text { (months) }\end{array}$ & $\begin{array}{c}\text { DFS } \\
\text { (months) }\end{array}$ \\
\hline \multirow[t]{2}{*}{ GITSG (36) } & Observation & 22 & 47 & 15 ( 2 years $)$ & 10.9 & 9 \\
\hline & 5-FU-CRT then 5-FU & 21 & 33 & 42 (2 years) & $20.0^{*}$ & 11 \\
\hline \multirow[t]{4}{*}{ EORTC (29) } & Observation & 57 & 36 & 10 (5 years, pancreas) & 12.6 (pancreas) & \\
\hline & & 103 & & 22 (5 years, all) & 19.0 (all) & \\
\hline & 5-FU-CRT & 63 & 36 & 20 (5 years, pancreas) & 17.1 (pancreas) & \\
\hline & & 104 & & $25(5$ years all $)$ & 24.5 (all) & \\
\hline \multirow[t]{2}{*}{ ESPAC1-2X2 (37) } & No CT vs. CT & 142 vs. 147 & & 8 vs. 21 (5 years) & 15.5 vs. 20.1 & $16 v s .19$ \\
\hline & No CRT vs. CRT & 144 vs. 145 & & 20 vs. 10 (5 years) & $17.9 v s .15 .9$ & 16 vs. 19 \\
\hline \multirow[t]{2}{*}{ RTOG 97-04 (38) } & $5-\mathrm{FU}+5-\mathrm{FU}-\mathrm{CRT}$ then $5-\mathrm{FU}$ & 230 & 28 & $22(3$ years $)$ & 16.9 & \\
\hline & GEM +5FU-CRT then GEM & 221 & 23 & 31 (3 years) & 20.5 & \\
\hline \multirow[t]{2}{*}{ ESPAC-3 (39) } & $5-\mathrm{FU}$ & 551 & & 48 (2 years) & 23.0 & 14.1 \\
\hline & GEM & 537 & & 29 (2 years) & 23.6 & 14.3 \\
\hline \multirow[t]{2}{*}{ CONKO-001 (40) } & Observation & 182 & & 10.4 (5 years) & 20.2 & 6.7 \\
\hline & GEM & 186 & & 20.7 (5 years) & 22.8 & 13.4 \\
\hline
\end{tabular}

CRT: Chemoradiotherapy; CT: chemotherapy; GEM: gemcitabine; 5-FU: 5-fluorouracil; CONKO: Chartie Onkologie; EORTC: European Organisation for the Research and Treatment of Cancer; ESPAC: European Study Group for Pancreatic Cancer; GITSG: Gastrointestinal Tumor Study Group; RTOG: Radiation Therapy Oncology Group. Significantly better at $* p<0.05$.

Table VII. Summary of studies evaluating the impact of margin status on survival.

\begin{tabular}{|c|c|c|c|c|c|c|c|}
\hline $\begin{array}{l}\text { Reference } \\
\text { (Fist author/year) }\end{array}$ & $\begin{array}{l}\text { No. of } \\
\text { patients }\end{array}$ & RM status & $\mathrm{R} 1$ rate $(\%)$ & $\begin{array}{l}\text { Median survival } \\
\text { R1/R2 (months) }\end{array}$ & $\begin{array}{l}\text { Median survival } \\
\text { R0 (months) }\end{array}$ & $\begin{array}{c}\text { Local recurrence } \\
\text { rate }(\%)\end{array}$ & $\begin{array}{c}\text { Distant metastasis } \\
\text { rate }(\%)\end{array}$ \\
\hline Menon (2009) (23) & 27 & $\mathrm{R} 1$ & 82 & 14 & $55^{*}$ & & \\
\hline Raut (2007) (18) & 360 & $\mathrm{R} 1$ & 17 & 22 & $28 *$ & $\begin{array}{l}\text { R1: } 6.7 \\
\text { R0: } 8.0\end{array}$ & $\begin{array}{l}45 \\
42\end{array}$ \\
\hline Verbeke (2006) (7) & 26 & $\mathrm{R} 1$ & 85 & 11 & $37 *$ & & \\
\hline Neoptolemos (2001) (10) & 541 & $\mathrm{R} 1$ & 19 & 11 & $17^{*}$ & & \\
\hline Sohn (2000) (26) & 616 & $\mathrm{R} 1$ & 30 & 12 & $19 *$ & & \\
\hline Yeo (1995) (25) & 201 & $\mathrm{R} 1, \mathrm{R} 2$ & 29 & 10 & $18^{*}$ & & \\
\hline Willet (1993) (15) & 72 & $\mathrm{R} 1$ & 51 & 12 & $20 *$ & $\begin{array}{l}\text { LCR: R1: } 22 \\
\text { R0: } 43\end{array}$ & $\begin{array}{c}\text { FFDM: } 19 \text { ( } 3 \text { years } \\
37 \text { ( } 5 \text { years })\end{array}$ \\
\hline Current study & 62 & $\mathrm{R} 1$ & 100 & 22 & - & 42 & 84 \\
\hline
\end{tabular}

RM: Resection margin; R0: clear margins; R1: microscopic margin involvement; R2: gross margin involvement; LCR: local control rate; FFDM: free from distant metastases. Significantly better at $* p<0.05$.

months in R1 patients. However, the studies listed in Table VII and the randomized controlled trials reported in Table VI did not stratify the patients for treatment depending on the resection margin status.

Our current study retrospectively analyzed only patients with R1 resection for survival outcomes and recurrence patterns. The survival outcomes determined by our present analysis are superior to those of previous reports presented in Table VII, except for the study of Raut et al. (18). When we compared our current results with the historical R0 group in Table VI, we found similar or slightly poorer survival outcomes; however, an exact comparison was difficult because of large variations. Conflicting conclusions are also widespread among different centers on the impact of the margin status on the patterns of recurrence for resected pancreatic cancer. Raut et al. reported that resection margin status did not affect the patterns of first recurrence (18). However, some studies have reported an association between the location of the positive resection margin and the site of local recurrence. Gnerlich et al. reported that the posterior margin was found to be the only site of R1 that influenced survival (27). Jamieson et al. indicated that the transection margin of the pancreatic neck and the superior mesenteric artery-facing margin were the only significant prognostic sites of R1 (5).

The local recurrence rate in our present study was $42 \%$, which was consistent with data in the literature. Historically, local recurrence rates after adjuvant therapy are known to be 
a

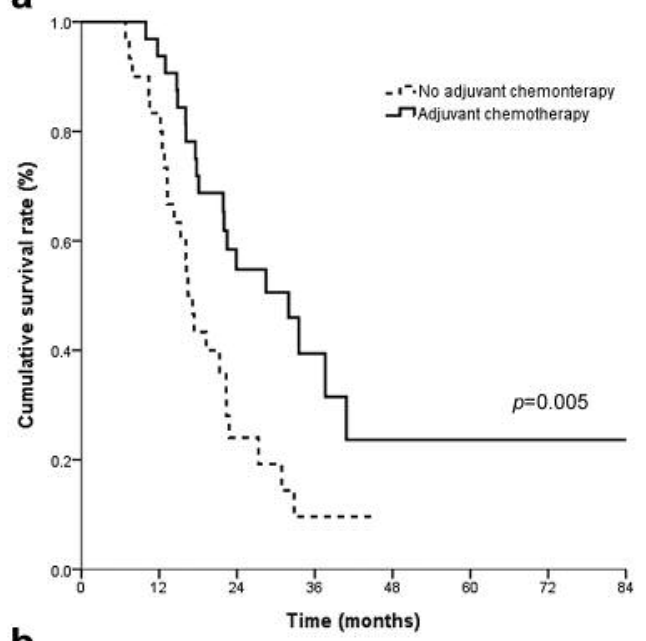

b

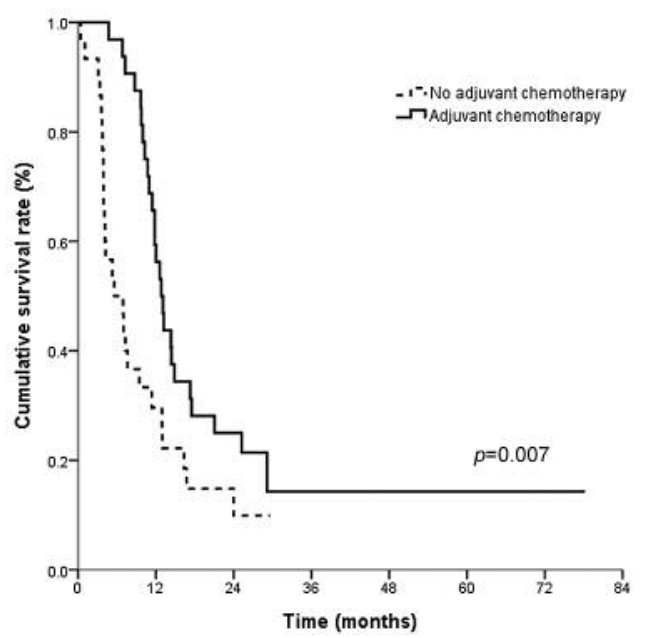

C

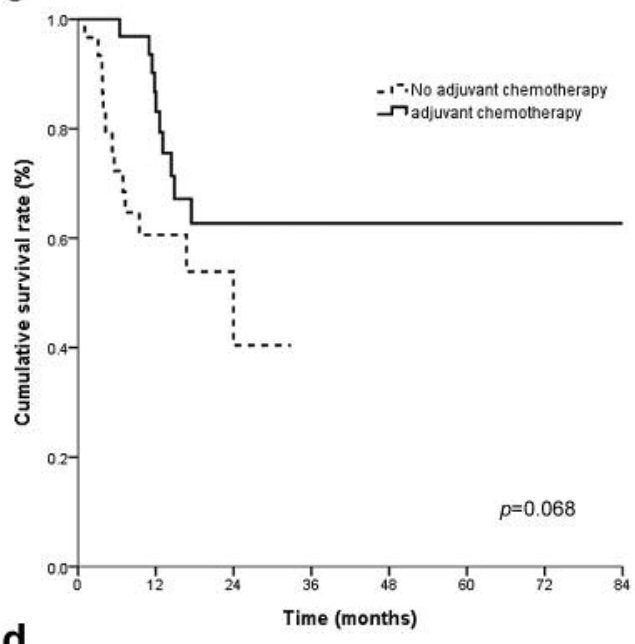

d

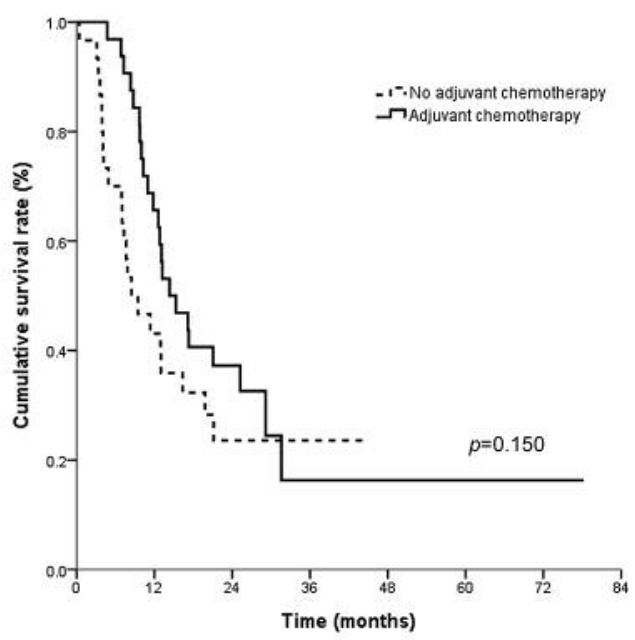

Figure 4. Comparison of overall (a), disease-free (b), local recurrence-free (c) and distant metastasis-free (d) survival according to adjuvant chemotherapy.

$20-60 \%$ for patients with resectable pancreatic cancer $(16$, $28,29)$. Discrepancies in the local recurrence rate and survival outcome in patients with $\mathrm{R} 1$ might be due to the different treatment modalities used in different studies. As mentioned earlier, there is no established treatment for postoperative adjuvant treatment in patients with pancreatic cancer depending on their resection margin status. In particular, the role of adjuvant RT is still controversial.

We investigated the prognostic factors affecting survival for selected patients with R1 who received adjuvant RT. Among these factors, the postoperative CA19-9 level and the administration of adjuvant chemotherapy affected the OS and DFS outcomes (Figures 4 and 5). In a previous retrospective study by Montgomery et al., the postoperative CA19-9 level was reported to be of the most significant prognostic factors
(30). Patients whose level of CA19-9 normalized 3-6 months after surgery had a significantly longer median survival in that study. In addition, patients with postoperative levels lower than $180 \mathrm{U} / \mathrm{ml}$ at 1-3 months had significantly improved survival compared to those with a higher level, and similar survival to those with a normalized CA19-9. In addition, a phase III trial (RTOG 9704) undertook a prospective analysis of CA19-9 levels in patients treated with adjuvant chemoradiotherapy (31). That study confirmed the prognostic importance of the post-resection CA19-9 level after surgery with curative intent in patients with pancreatic cancer. In our current study, the postoperative CA19-9 level was found to be a significant prognostic factor by multivariate analysis. However, unlike other reports, our current analysis revealed that the postoperative CA19-9 level 

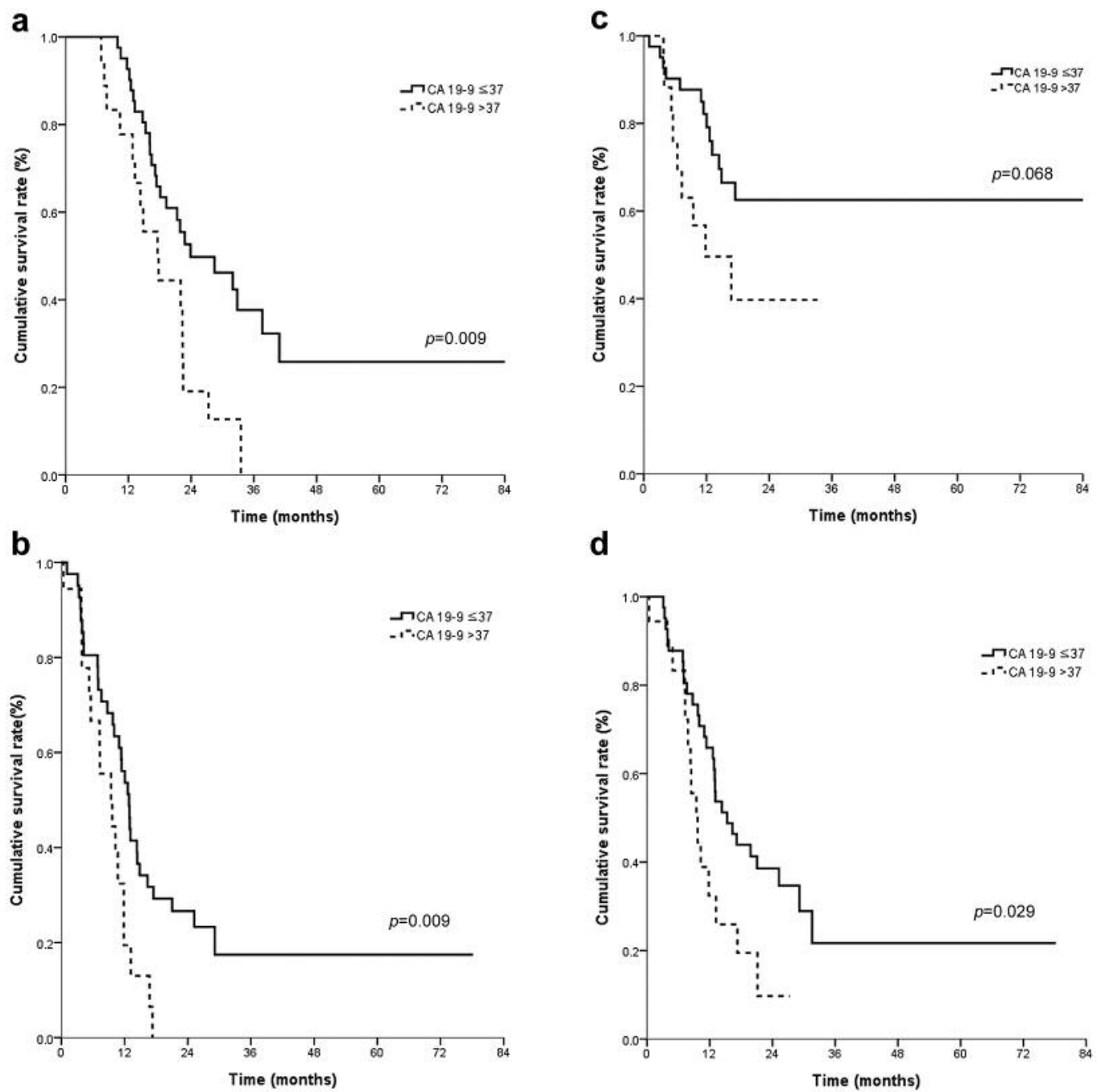

Figure 5. Comparison of overall (a), disease-free (b), local recurrence-free and (c) distant metastasis-free (d) survival according to postoperative level of carbohydrate antigen 19-9 (CA19-9), evaluated within 3 months of resection.

was a significant factor for OS and DFS outcomes when normalized to $37 \mathrm{U} / \mathrm{ml}$ or less. The CA19-9 level was measured about 1 month after surgery in the current study. In the present study, major vessel resection and vascular invasion were not found to be prognostic factors. However, several studies have reported that major vascular involvement $(8,32)$, including portal vein invasion (33) and vascular resection $(34,35)$, are prognostic factors for survival in pancreatic cancer.

Adjuvant chemotherapy was also a prognostic factor for OS and DFS in our present results (Figure 5). Our study targeted to patients with postoperative R1 who received postoperative radiotherapy; 58 patients in our series (94\%) received concurrent chemoradiotherapy. Adjuvant chemotherapy followed by concurrent chemoradiotherapy was performed in 32 patients $(52 \%)$. Two randomized trials that have previously conducted maintenance chemotherapy after chemoradiotherapy were GITSG (36) and RTOG 9704 (38). In the GITSG trial, there was a survival benefit in patients treated with adjuvant chemoradiotherapy followed by maintenance chemotherapy (36). As mentioned in Table VI, the RTOG 9704 trial showed that addition of gemcitabine to adjuvant fluorouracil chemoradiotherapy improves survival for patients with resected pancreatic adenocarcinoma, although this improvement was not statistically significant (38). In fact, it is difficult to draw definite conclusions because no gold-standard postoperative adjuvant treatment has been established. However, several randomized trials have suggested the efficacy of maintenance chemotherapy after adjuvant chemoradiotherapy. We also found a survival benefit in patients who underwent maintenance chemotherapy in our current study. 
No studies to date of R0 and R1 patients have been conclusive. We, thus, believe that it is necessary to conduct RT targeting by stratifying patients in accordance with their survival and local recurrence probability. An exact and consistent pathological examination should be a prerequisite to this. In conclusion, PORT shows a relatively favorable survival outcome in patients with pancreatic cancer with a microscopic positive resection margin, consistent with findings in the literature. Adjuvant chemotherapy and postoperative CA19-9 level after concurrent chemoradiotherapy or RT alone are significant prognostic factors for OS and DFS in patients with resection marginpositive pancreatic cancer.

\section{References}

1 Jemal A, Siegel R, Ward E, Hao Y, Xu J, Murray T and Thun MJ: Cancer statistics, 2008. CA Cancer J Clin 58: 71-96, 2008.

2 Li D, Xie K, Wolff R and Abbruzzese JL: Pancreatic cancer. The Lancet 363: 1049-1057, 2004.

3 Geer RJ and Brennan MF: Prognostic indicators for survival after resection of pancreatic adenocarcinoma. Am J Surg 165: 68-73, 1993.

4 Campbell F, Smith RA, Whelan P, Sutton R, Raraty M, Neoptolemos JP and Ghaneh P: Classification of R1 resections for pancreatic cancer: the prognostic relevance of tumour involvement within $1 \mathrm{~mm}$ of a resection margin. Histopathology 55: 277-283, 2009.

5 Jamieson NB, Foulis AK, Oien KA, Going JJ, Glen P, Dickson EJ, Imrie CW, McKay CJ and Carter R: Positive mobilization margins alone do not influence survival following pancreaticoduodenectomy for pancreatic ductal adenocarcinoma. Ann Surg 251: 1003-1010, 2010.

6 Hartwig W, Hackert T, Hinz U, Gluth A, Bergmann F, Strobel $\mathrm{O}$, Buchler MW and Werner J: Pancreatic cancer surgery in the new millennium: better prediction of outcome. Ann Surg 254: 311-319, 2011.

7 Verbeke CS, Leitch D, Menon KV, McMahon MJ, Guillou PJ and Anthoney A: Redefining the $\mathrm{R} 1$ resection in pancreatic cancer. Br J Surg 93: 1232-1237, 2006.

8 Allema JH, Reinders ME, van Gulik TM, Koelemay MJ, van Leeuwen DJ, de Wit LT, Gouma DJ and Obertop H: Prognostic factors for survival after pancreaticoduodenectomy for patients with carcinoma of the pancreatic head region. Cancer 75: 20692076, 1995.

9 Yeo CJ, Cameron JL, Sohn TA, Lillemoe KD, Pitt HA, Talamini MA, Hruban RH, Ord SE, Sauter PK and Coleman J: Six hundred fifty consecutive pancreaticoduodenectomies in the 1990s: pathology, complications, and outcomes. Ann Surg 226: 248, 1997.

10 Neoptolemos JP, Stocken DD, Dunn JA, Almond J, Beger HG, Pederzoli P, Bassi C, Dervenis C, Fernandez-Cruz L and Lacaine $\mathrm{F}$ : Influence of resection margins on survival for patients with pancreatic cancer treated by adjuvant chemoradiation and/or chemotherapy in the ESPAC-1 randomized controlled trial. Ann Surg 234: 758, 2001

11 Wagner M, Redaelli C, Lietz M, Seiler CA, Friess H and Buchler MW: Curative resection is the single most important factor determining outcome in patients with pancreatic adenocarcinoma. Br J Surg 91: 586-594, 2004.

12 Matsuno S, Egawa S and Unno M: R0 resection for ductal pancreatic cancer - Japanese experience. Am J Surgery 194: S110-S114, 2007.

13 Katz MH, Merchant NB, Brower S, Branda M, Posner MC, William Traverso L, Abrams RA, Picozzi VJ, Pisters PW and American College of Surgeons Oncology G: Standardization of surgical and pathologic variables is needed in multicenter trials of adjuvant therapy for pancreatic cancer: results from the ACOSOG Z5031 trial. Ann Surg Oncol 18: 337-344, 2011.

14 Stocken DD, Buchler MW, Dervenis C, Bassi C, Jeekel H, Klinkenbijl JH, Bakkevold KE, Takada T, Amano H, Neoptolemos JP and Pancreatic Cancer Meta-analysis Group: Meta-analysis of randomised adjuvant therapy trials for pancreatic cancer. Br J Cancer 92: 1372-1381, 2005.

15 Willett CG, Lewandrowski K, Warshaw AL, Efird $\mathrm{J}$ and Compton CC: Resection margins in carcinoma of the head of the pancreas. Implications for radiation therapy. Ann Surg 217: 144, 1993.

16 Griffin JF, Smalley SR, Jewell W, Paradelo JC, Reymond RD, Hassanein RE and Evans RG: Patterns of failure after curative resection of pancreatic carcinoma. Cancer 66: 56-61, 1990.

17 Winter JM, Cameron JL, Campbell KA, Arnold MA, Chang DC, Coleman J, Hodgin MB, Sauter PK, Hruban RH, Riall TS, Schulick RD, Choti MA, Lillemoe KD and Yeo CJ: 1423 pancreaticoduodenectomies for pancreatic cancer: A singleinstitution experience. J Gastrointest Surg 10: 1199-1210; discussion 1210-1191, 2006.

18 Raut CP, Tseng JF, Sun CC, Wang H, Wolff RA, Crane CH, Hwang R, Vauthey JN, Abdalla EK, Lee JE, Pisters PW and Evans DB: Impact of resection status on pattern of failure and survival after pancreaticoduodenectomy for pancreatic adenocarcinoma. Ann Surg 246: 52-60, 2007.

19 Esposito I, Kleeff J, Bergmann F, Reiser C, Herpel E, Friess H, Schirmacher $\mathrm{P}$ and Buchler MW: Most pancreatic cancer resections are R1 resections. Ann Surg Oncol 15: 1651-1660, 2008.

20 Verbeke CS and Menon KV: Redefining resection margin status in pancreatic cancer. HPB 11: 282-289, 2009.

21 Sobin LH and Fleming ID: TNM Classification of Malignant Tumors, (1997). Cancer 80: 1803-1804, 1997.

22 Pancreatric Section BSoG, Pancreatic Society of Great B, Ireland, Association of Upper Gastrointestinal Surgeons of Great B, Ireland, Royal College of P and Special Interest Group for Gastro-Intestinal R: Guidelines for the management of patients with pancreatic cancer periampullary and ampullary carcinomas. Gut 54(Suppl 5): v1-16, 2005.

23 Menon KV, Gomez D, Smith AM, Anthoney A and Verbeke CS: Impact of margin status on survival following pancreatoduodenectomy for cancer: the Leeds Pathology Protocol (LEEPP). HPB 11: 18-24, 2009.

24 Wagner M, Redaelli C, Lietz M, Seiler C, Friess H and Büchler $\mathrm{M}$ : Curative resection is the single most important factor determining outcome in patients with pancreatic adenocarcinoma. Br J Surg 91: 586-594, 2004.

25 Yeo CJ, Cameron JL, Lillemoe KD, Sitzmann JV, Hruban RH, Goodman SN, Dooley WC, Coleman J and Pitt HA: Pancreaticoduodenectomy for cancer of the head of the pancreas. 201 patients. Ann Surg 221: 721-731; discussion 731-723, 1995. 
26 Sohn TA, Yeo CJ, Cameron JL, Koniaris L, Kaushal S, Abrams RA, Sauter PK, Coleman J, Hruban RH and Lillemoe KD: Resected adenocarcinoma of the pancreas-616 patients: results, outcomes, and prognostic indicators. J Gastrointest Surg 4: 567579,2001

27 Gnerlich JL, Luka SR, Deshpande AD, Dubray BJ, Weir JS, Carpenter DH, Brunt EM, Strasberg SM, Hawkins WG and Linehan DC: Microscopic margins and patterns of treatment failure in resected pancreatic adenocarcinoma. Arch Surg 147: 753-760, 2012

28 Tepper J, Nardi G and Sutt H: Carcinoma of the pancreas: review of MGH experience from 1963 to 1973. Analysis of surgical failure and implications for radiation therapy. Cancer 37: 1519-1524, 1976.

29 Smeenk HG, van Eijck CH, Hop WC, Erdmann J, Tran KC, Debois M, van Cutsem E, van Dekken H, Klinkenbijl JH and Jeekel J: Long-term survival and metastatic pattern of pancreatic and periampullary cancer after adjuvant chemoradiation or observation: long-term results of EORTC trial 40891. Ann Surg 246: 734-740, 2007.

30 Montgomery RC, Hoffman JP, Riley LB, Rogatko A, Ridge JA and Eisenberg BL: Prediction of recurrence and survival by postresection CA 19-9 values in patients with adenocarcinoma of the pancreas. Ann Surg Oncol 4: 551-556, 1997.

31 Berger AC, Garcia M Jr., Hoffman JP, Regine WF, Abrams RA, Safran H, Konski A, Benson AB, 3rd, MacDonald J and Willett CG: Postresection CA 19-9 predicts overall survival in patients with pancreatic cancer treated with adjuvant chemoradiation: a prospective validation by RTOG 9704. J Clin Oncol 26: 59185922, 2008.

32 Bouvet M, Gamagami RA, Gilpin EA, Romeo O, Sasson A, Easter DW and Moossa AR: Factors influencing survival after resection for periampullary neoplasms. Am J Surg 180: 13-17, 2000 .

33 Jarufe NP, Coldham C, Mayer AD, Mirza DF, Buckels JA and Bramhall SR: Favourable prognostic factors in a large UK experience of adenocarcinoma of the head of the pancreas and periampullary region. Dig Surg 21: 202-209, 2004.

34 Jamieson NB, Chan NI, Foulis AK, Dickson EJ, McKay CJ and Carter CR: The prognostic influence of resection margin clearance following pancreaticoduodenectomy for pancreatic ductal adenocarcinoma. J Gastrointest Surg 17: 511-521, 2013.
35 Sugiura T, Uesaka K, Mihara K, Sasaki K, Kanemoto H, Mizuno $\mathrm{T}$ and Okamura $\mathrm{Y}$ : Margin status, recurrence pattern, and prognosis after resection of pancreatic cancer. Surgery 154: 1078-1086, 2013.

36 Kaiser MH and Ellenberg SS: Pancreatic cancer: adjuvant combined radiation and chemotherapy following curative resection. Arch Surg 120: 899-903, 1985.

37 Neoptolemos JP, Stocken DD, Friess H, Bassi C, Dunn JA, Hickey H, Beger H, Fernandez-Cruz L, Dervenis C, Lacaine F, Falconi M, Pederzoli P, Pap A, Spooner D, Kerr DJ and Buchler MW: A randomized trial of chemoradiotherapy and chemotherapy after resection of pancreatic cancer. N Engl J Med 350: 1200-1210, 2004.

38 Regine WF, Winter KA, Abrams RA, Safran H, Hoffman JP, Konski A, Benson AB, Macdonald JS, Kudrimoti MR and Fromm ML: Fluorouracil vs gemcitabine chemotherapy before and after fluorouracil-based chemoradiation following resection of pancreatic adenocarcinoma: a randomized controlled trial. JAMA 299: 1019-1026, 2008.

39 Neoptolemos JP, Stocken DD, Bassi C, Ghaneh P, Cunningham D, Goldstein D, Padbury R, Moore MJ, Gallinger S and Mariette C: Adjuvant chemotherapy with fluorouracil plus folinic acid $v s$. gemcitabine following pancreatic cancer resection: a randomized controlled trial. JAMA 304: 1073-1081, 2010.

40 Oettle H, Neuhaus P, Hochhaus A, Hartmann JT, Gellert K, Ridwelski K, Niedergethmann M, Zulke C, Fahlke J, Arning MB, Sinn M, Hinke A and Riess H: Adjuvant chemotherapy with gemcitabine and long-term outcomes among patients with resected pancreatic cancer: the CONKO-001 randomized trial. JAMA 310: 1473-1481, 2013.
Received November 24, 2016

Revised January 15, 2017

Accepted January 18, 2017 